\title{
In Vivo Evaluation of Complex Biogenic Silver Nanoparticle and Enoxaparin in Wound Healing
}

\author{
P. D. Marcato, ${ }^{1,2}$ L. B. De Paula, ${ }^{3,4}$ P. S. Melo, ${ }^{3,4}$ I. R. Ferreira, ${ }^{3}$ A. B. A. Almeida, ${ }^{4,5}$ \\ A. S. Torsoni, ${ }^{6}$ and O. L. Alves ${ }^{1}$ \\ ${ }^{1}$ Solid State Chemistry Lab. (LQES), Chemistry Institute, Universidade Estadual de Campinas, \\ CP 6154, 13083-970 Campinas, SP, Brazil \\ ${ }^{2}$ Nanobiolab, School of Pharmaceutical Sciences of Riberão Preto, Universidade de São Paulo, 14030-940 Ribeirão Preto, SP, Brazil \\ ${ }^{3}$ Biochemistry Department, Universidade Estadual de Campinas, CP 6109, 13083-970 Campinas, SP, Brazil \\ ${ }^{4}$ Faculdade Metrocamp, 13035-500 Campinas, SP, Brazil \\ ${ }^{5}$ Hospital Sobrapar, CP 6028, 13083-880 Campinas, SP, Brazil \\ ${ }^{6}$ School of Applied Sciences, Universidade Estadual de Campinas, CP 1068, 13484-350 Limeira, SP, Brazil
}

Correspondence should be addressed to P. D. Marcato; pmarcato@gmail.com

Received 10 December 2014; Revised 27 February 2015; Accepted 3 March 2015

Academic Editor: Jin-Ho Choy

Copyright (C) 2015 P. D. Marcato et al. This is an open access article distributed under the Creative Commons Attribution License, which permits unrestricted use, distribution, and reproduction in any medium, provided the original work is properly cited.

\begin{abstract}
The burns treatment is difficult, uncomfortable for the patient, and expensive for health system. Due to antimicrobial properties of silver nanoparticles (AgNP), these particles can avoid bacterial infection in wound and accelerate the wound healing. Furthermore, the complexation of AgNP with enoxaparin (low molecular weight heparin) may improve the healing process of lesions due to anti-inflammatory and angiogenic activity of enoxaparin (Enox). The aim of this study was evaluated the activity and toxicity of biogenic AgNP and AgNP complexed with Enox in in vivo burn wound model. AgNP was produced by biosynthesis method using Fusarium oxysporum. AgNP (20-40 nm) exhibited high stability due to protein capping around the particles that was confirmed by TEM, fluorescence spectroscopy, and FTIR. The wound contraction in in vivo model, after 28 days of treatment, was 55, 89, 91, and 95\% for control, Enox, AgNP, and AgNP-Enox groups, respectively. No clear toxic effects in the biochemistry and hematological parameters were verified in all treated groups. However, in the AgNP-Enox group, a statistically significant increase in the urea levels was observed indicating increased proteolysis due to inflammation process. The results demonstrated that the complex AgNP-Enox is interesting for wound healing decreasing the time of lesions healing.
\end{abstract}

\section{Introduction}

Millions of people worldwide are burned every year. The current treatment of second and third degree burns is complex, uncomfortable for the patient and costly to the health system. Mortality from burns is estimated at $5 \%$ to $8.4 \%$ and for burns of over $30 \%$ of body surface is around $55 \%$ [1]. In the United States, 7.5 billions of dollars by year is spent in treatment of burn wound infections [2]. Further, the sequels of burns affect the life quality and produce social and emotional impact on patients [1]. However, the wound healing process is a complex process that includes some phases: haemostasis, inflammation, proliferation, pithelisation, maturation, and remodelling of the scar tissue [3-5]. In these phases numerous cell-signalling events are required for a wound efficient repair [6]. Thus, products that improve or accelerate the wound healing phases are interesting to burn treatment. An example is the topical or parental application of heparin [711]. Heparin and enoxaparin (low molecular weight heparin) are used as anticoagulant in the thrombosis treatment [12]. Heparin had been studied to burn treatment in humans and animals showing significant therapeutic results $[13,14]$. This drug can be interesting to burn and ulcers treatment because enoxaparin (Enox) exhibits anti-inflammatory effect, reduces local pain, promotes angiogenesis and epithelialization, restores the collagen, has anticoagulant activity, 
and accelerates the healing process indicating it to be an interesting drug for burn treatment $[9,15,16]$. However, the application of Enox can lead to bleeding, thrombocytopenia and allergy effect [8]. Thus, for topical application of heparin or Enox the positive and negative effects should be evaluated and its systemic absorption needs to be avoided.

A great problem in the burn healing is the bacterial contamination. This infection hinders the wound healing and is responsible for $75 \%$ of all deaths in patients with burns exceeding $40 \%$ of the total body surface area [17]. Grampositive bacteria such as Staphylococcus aureus gram-negative bacteria like Escherichia coli and Pseudomonas aeruginosa are common in burnt surfaces. The presence of bacteria, mainly multiresistant organisms and bacterial biofilms, in the wound burn delays the wound-healing process because of competing with host cells for nutrients and oxygen. Furthermore, their waste products are also toxic to host cells $[18,19]$. Thus, a product that improves the wound healing and exhibits antibacterial properties can be more efficient and interesting to burn treatment. In this way, silver ions or silver nanoparticles are interesting to burn treatment due to their high antimicrobial activity. Silver has been used for a century due to its great antimicrobial activity against bacteria, viruses, and fungi. Furthermore, the potential antiinflammatory effect of silver and its effects in accelerating wound healing were recently shown $[5,6,20-24]$. Nowadays, silver sulfadiazine is used in the burn treatment in order to avoid the bacterial contamination. However, studies show that this treatment is archaic and can increase the patient risk to develop leucopenia, neutropenia, erythema multiforme, crystalluria, and methemoglobinemia. Furthermore, nephroand hepatic toxicity is commonly observed during the treatment [25-27]. Thus, new formulations have been studied such as silver nanoparticles. The antimicrobial activity of silver nanoparticles is higher than silver ions due to their small size and high surface-to-volume ratio [17, 28]. Furthermore, silver nanoparticles show lower ecotoxicity than silver ions [29]. Thus, the amount and time of burn treatment can be decreased when using silver nanoparticles; the environment impact will also decrease. Besides the antimicrobial activity of silver nanoparticles, these particles can accelerate the wound healing by its anti-inflammatory activity and its effect in cytokines modulation [6]. Wright et al. [30], in the studied porcine model of wound healing, verified that wound dressings with silver showed antibacterial activity and significantly promoted wound healing with rapid neovascularisation and suppression of metalloproteinases. Similarly, Tian et al. [6] verified that silver nanoparticles applied topically in animal burn model were able to avoid antibacterial contamination, reduce wound inflammation, and modulate the fibrogenic cytokines, contributing for the wound healing. Thus, wound healing has been studied with chitosan membrane with silver nanoparticles [31, 32], nanofibers with silver nanoparticles [2], and gel with silver nanoparticles [6, 24], showing it to be an interesting alternative for burn treatment. Furthermore, silver ions and silver nanoparticles are used in several products on the market (more than 200 products in the world) and its use should be evaluated due to its toxic effect [33-35]. In in vitro and in vivo assays it was observed that silver ions and silver nanoparticles exhibit toxic effects [28]. This effect can be related with production of reactive oxygen species (ROS) that can disrupt the mitochondrial respiratory chain and stop the ATP synthesis, which in turn causes DNA damage or the silver disrupting the cell membrane [36, 37]. Thus, the toxicity of silver nanoparticles and its penetration in skin damaged need to be investigated before its application in wound. Therefore, in this study, the activity and toxicity of biogenic silver nanoparticles (AgNP) and AgNP complexed with enoxaparin (Enox) were evaluated in in vivo third degree burn wound model. Biochemistry and hematological analysis was carrying out to evaluate the toxic effect of formulations and the silver amount in different organs was also analyzed. The results showed that the complex AgNP-Enox accelerated the wound healing indicating great advantages of this system in burn treatment.

\section{Methods}

2.1. Silver Nanoparticles Production. F. oxysporum strain (551) from ESALQ-USP, Genetic and Molecular Biology Laboratory, Piracicaba, SP, Brazil, was used. The fungal inoculates were prepared in a malt extract $2 \%$ and yeast extract $0.5 \%$ at $28^{\circ} \mathrm{C}$ in Petri plates. For silver nanoparticles production, approximately $10 \mathrm{~g}$ of $F$. oxysporum biomass was taken in a conical flask containing $100 \mathrm{~mL}$ of distilled water. The system was kept at $28^{\circ} \mathrm{C}$ by $72 \mathrm{~h}$ and, afterwards, the aqueous solution (fungal filtrated) was separated from biomass by filtration. In this fungal filtrated $\mathrm{AgNO}_{3}\left(10^{-2} \mathrm{~mol} \cdot \mathrm{L}^{-1}\right)$ was added and kept for several hours at $28^{\circ} \mathrm{C}[38,39]$. The particles formation was followed by absorption measured in an UVVis spectrophotometer (HP8542A) at $440 \mathrm{~nm}$.

2.2. Particle Size and Zeta Potential. The average particle size (number average size) and size distribution were measured by photon correlation spectroscopy (PCS) (Nano ZS Zetasizer, Malvern Instruments Corp.) at $25^{\circ} \mathrm{C}$ in polystyrene cuvettes with path lengths of $10 \mathrm{~mm}$. The particles size and particles concentration were also measured by nanoparticle tracking analysis (NTA) using the Nanosight LM after the dilution of particles in water. The zeta potential was measured in capillary cells with path lengths of $10 \mathrm{~mm}$, using the Nano ZS Zetasizer. Measurements were performed with silver nanoparticle dispersion diluted with $\mathrm{KCl}$ solution $\left(10^{-3} \mathrm{~mol} \cdot \mathrm{L}^{-1}\right)$.

2.3. Protein Characterization. The protein capping around silver nanoparticles was characterized by fluorescence spectroscopy (Perkin Elmer, LS 55) and by Fourier transform infrared spectroscopy (FTIR) (FTLA 2000). For fluorescence analysis, silver nanoparticles dispersion was diluted with deionized water $(1: 1)$. The excitation wavelength used was $280 \mathrm{~nm}$ that corresponds with the excitation wavelength of tryptophan and tyrosine amino acid. The FTIR analysis was made in ART mode after the lyophilization of silver dispersion.

2.4. Transmission Electron Microscopy (TEM) Analysis. Silver nanoparticles were characterized by transmission electron 
microscopy and elemental spectroscopy imaging (ESI) (Carl Zeiss Libra, $120 \mathrm{KeV}$ ). For the analysis, one drop of the particle dispersion was deposited on carbon-coated parlodion films supported in 300 mesh copper grids (TedPella). Bright field images and the elemental distribution of silver nanoparticles were carried out.

2.5. Antimicrobial Activity of Silver Nanoparticles. Antimicrobial activity of silver nanoparticles was investigated by determining the minimum inhibitory concentration (MIC) on standard stocks of Staphylococcus aureus (ATCC 29213) and methicillin-resistant Staphylococcus aureus (BEC 9393). MIC values were determined by a microdilution test in a culture broth. A suspension of microorganisms containing about $10^{5} \mathrm{CFU} \mathrm{mL} \mathrm{mL}^{-1}$ was added to each well. The plates were incubated at $37^{\circ} \mathrm{C}$ for $24 \mathrm{~h}$. MIC was defined as the lowest silver nanoparticles concentration that inhibited visible growth after $24 \mathrm{~h}$ of incubation. A positive control (growth) formed by a culture broth containing microorganisms and a negative control (sterility) formed by a culture broth without microorganisms were included for each test. Each concentration was tested in triplicate.

2.6. Complexation of Biogenic Silver Nanoparticles with Enoxaparin. For complexation of AgNP with Enox, $1 \mathrm{mg} \cdot \mathrm{mL}^{-1}$ of Enox (Clexane, $60 \mathrm{mg} / 0.6 \mathrm{~mL}$ ) was added into the AgNP dispersion $\left(10^{-2} \mathrm{~mol} \cdot \mathrm{L}^{-1}\right)$ under magnetic stirring. The system was kept protected of the light and under magnetic agitation by $12 \mathrm{~h} \mathrm{[40].}$

2.7. In Vivo Activity and Toxicity Assay. Male Wistar rats, from the CEMIB-UNICAMP, were used respecting the Brazilian Law on Animal Experiments. The experimental protocol was approved by the University Committee on Animal Research at UNICAMP (process number 2311-1).

2.7.1. Thermal Injury Animals and Treatment. In this study, Wistar rats (250-300 g) were maintained in individual cages during the assay, with free access to food and water, under controlled conditions (room temperature at $22 \pm 2^{\circ} \mathrm{C} ; 12 \mathrm{hr}$ light/dark cycle). The thermal injury was performed in agreement with Tian et al. [6]. Briefly, rats were anesthetized with ketamine $(40 \mathrm{mg} / \mathrm{kg}$ ) and xylazine $(20 \mathrm{mg} / \mathrm{Kg})$ through intraperitoneal route. Afterwards, the hair of animals dorsal was shaved off and placed in an appropriately sized template device such that the shaved area of the skin on the animals' back was exposed. The template device was then lowered into a hot water bath $\left(90^{\circ} \mathrm{C}\right)$ to immerse the exposed skin area $\left(4 \mathrm{~cm}^{2}\right)$ in hot water for 10 seconds causing a third-degree thermal injury. Then, the animals received a subcutaneous injection of saline solution [41]. After the thermal injury, 4 treatments were used on the dorsal skin: free natrosol gel (control group), gel with silver nanoparticles (AgNP) (1.4 mg/g of gel), gel with Enox (Enox) $(1 \mathrm{mg} / \mathrm{g}$ of gel), and gel with AgNP-Enox (1.4 mg of AgNP-1 mg of Enox/g of gel). All formulation was prepared with no-ionic gel natrosol (hydroxyethylcellulose) (2\%). All the animals received the treatment twice a day. The animals were sacrificed in different days (7th, 14th, 21th, and 28th day after the thermal injury). In each day 6 animals each group was euthanized and its blood and 5 different organs (skin, kidney, spleen, lung, and liver) were collected. The wound contraction was macroscopically monitored using measurements of the diameter of the injured area, in centimeters, with a caliper (Mitutoyo). The measurements were done 24 hours after the burn induction (initial wound area) and after 28 days after induction. Data of wound size were expressed as percentage of the initial wound area.

\subsubsection{Biochemistry and Hematological Analysis}

(a) Biochemistry Parameters. To analyze the in vivo toxicity of formulation, biochemistry parameters (Urea, creatinine, aspartate aminotransferase (AST), and alanine aminotransferase (ALT)) were carrying out in blood serum using commercial kits: Katal for urea, AST, ALT analysis, and Laborlab for creatinine. All analyses were carried out in a Bioplus biochemical analyzer (Celm SB-190) at $37^{\circ} \mathrm{C}$.

(b) Hematological Parameters. Hematological parameters evaluated in this work were leukocyte, erythrocyte, and platelet counts and hemoglobin and white cells concentration. All blood samples were analyzed in an autohematology analyzer (Mindray, BC-2300). The platelet was counted using a Neubauer chamber.

(c) Histological Analysis. In the histological analysis, the damaged skin of the animals was removed and immersed in fixative solution ( $4 \%$ of phosphate-buffered paraformaldehyde) for 24 at room temperature. The specimens were then washed under running tap water and processed for histological embedding in paraffin. Longitudinal sections $(5 \mu \mathrm{m})$ were serially cut with a manual microtome and stained with hematoxylin-eosin ( $\mathrm{HE}$ ) for routine histology. The sections were examined by convencional light microscopy using a Leica FW 4500 B microscope.

(d) Inductively Coupled Plasma Optical Emission Spectroscopy (ICP-OES). Silver concentration in different organs (blood, skin, kidney, spleen, lung, and liver) was determined by ICP-OES. Briefly, organs samples (400 mg of organs) were digested with concentrated $\mathrm{HNO}_{3}$ and then $2 \mathrm{~mL}$ of $\mathrm{H}_{2} \mathrm{O}_{2}$ (30\%) was added. The system was heated until boiling and the digestion continued for approximately $3 \mathrm{~h}$. After, $5 \mathrm{~mL}$ of deionized water was added and the sample was analyzed by ICP-OES.

2.8. Statistical Analysis. Statistical analysis for the in vivo assay was carried out using One-way ANOVA for multiple comparisons. A post hoc test (Tukey) was employed for determining a significance level of $P<0.05$.

\section{Results and Discussion}

3.1. Biogenic Silver Nanoparticles. Silver nanoparticles with negative surface charge $(-22 \mathrm{mV})$ were produced in 28 hours exhibiting a plasmon band at $450 \mathrm{~nm}$ (Figure 1(a)). The high negative charge of particles increases its stability (more than 


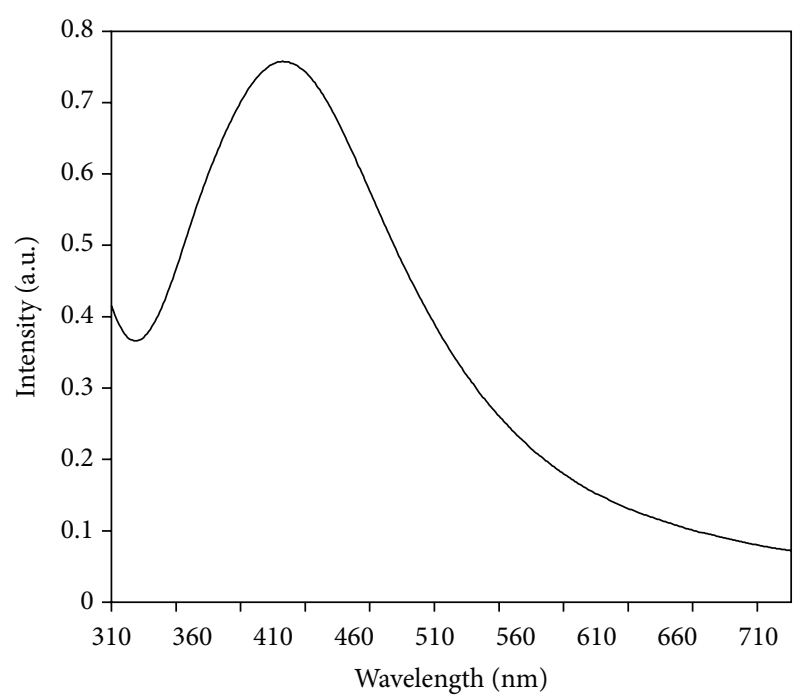

(a)

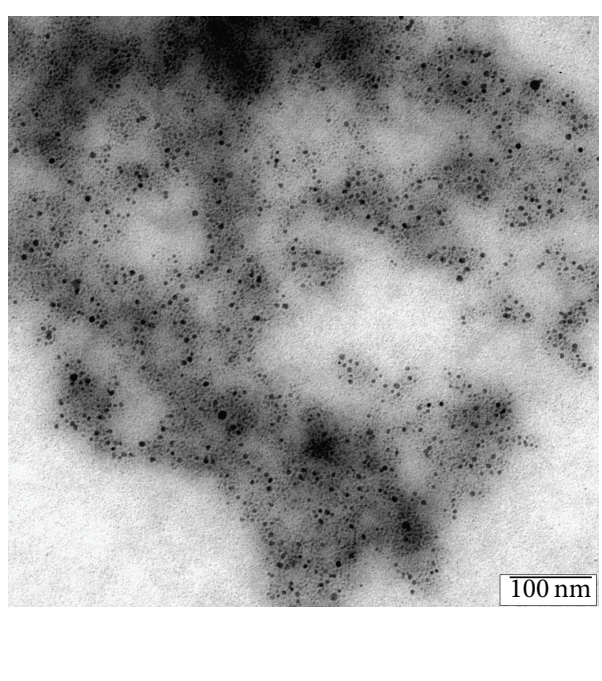

(b)

FIGURE 1: (a) UV-Vis spectrum of silver nanoparticles dispersion, (b) TEM Bright field image of the biogenic silver nanoparticles.

1 year) due to repulsion between the particles that avoid its aggregation. Homogeneous and spherical particles with 20-40 nm of size were observed by TEM (Figure 1(b)). The protein capping around the silver nanoparticles was observed by TEM-ESI as shown in Figure 2. The mapping of Ag atom (intense bright white points) shown in Figure 2(b) confirms that particles are formed by silver. Furthermore, the mapping, in the same region, of $\mathrm{N}$ and $\mathrm{S}$ atoms (clouds of white regions) observed around the silver nanoparticles (intense bright white points) can be attributed to protein of the fungus (Figures 2(c) and 2(d)). Some authors, in the literature, suggest that AgNP can bind to proteins of microorganisms either through free amine groups or of cysteine residues of the proteins [42, 43].

Fluorescence analysis also indicated the protein in the particles dispersion. Figure 3 shows the fluorescence spectrum of fungal filtrated before the addition of $\mathrm{AgNO}_{3}$ (Figure 3(a)) and after AgNP formation (Figure 3(b)). In the fungal filtrated can be observed only one band at $375 \mathrm{~nm}$ related to tryptophan or tyrosine amino acid from proteins secreted by the fungus. However, in the AgNP dispersion three bands were observed at $360 \mathrm{~nm}, 421 \mathrm{~nm}$, and $487 \mathrm{~nm}$. The first one can be attributed to the tryptophan or tyrosine amino acid from the fungal proteins. The blue shift in the maximum fluorescence emission at wavelength of tryptophan/tyrosine (375 to $360 \mathrm{~nm}$ ) can be related to the conformational changes of fungal proteins during its binding with AgNP. This change indicates that the tryptophan/tyrosine surroundings were changed to a more polar environment when complexed with AgNP [44, 45]. Other two bands (421 and $487 \mathrm{~nm}$ ) correspond to the metal-ligand interactions, which, in this case, is interaction between Ag and fungal proteins, confirming the protein capping around silver nanoparticles, as well as being also observed by TEM.
Similar results were obtained by Fayaz et al. [46] with silver nanoparticles produced by the fungus Trichoderma viride. The presence of protein around the AgNP is very important because it enhances the particles stability without addition of surfactant in the preparation.

The presence of peptide linkage was verified by FTIR (Figure 4). An intense and broad band at $3233 \mathrm{~cm}^{-1}$ was observed in FTIR spectrum, which can be assigned to N$\mathrm{H}$ stretching frequency due to peptide linkages present in the fungus proteins. Furthermore, bands at 2931, 1624, and $1535 \mathrm{~cm}^{-1}$ assigned to the amide-II band, which arose due to carbonyl stretch and $-\mathrm{N}-\mathrm{H}$ - stretch vibrations in the amide linkages of the proteins. The bands at $1317 \mathrm{~cm}^{-1}, 1060 \mathrm{~cm}^{-1}$, and $1031 \mathrm{~cm}^{-1}$ can be assigned to $\mathrm{C}-\mathrm{N}$ stretching which are generally found in protein $[42,43]$.

3.2. Antibacterial Activity of Silver Nanoparticles. The antimicrobial activity of AgNP against S. aureus and methicillinresistant $S$. aureus (MRSA) was evaluated. In this study, a low AgNP concentration inhibited the growth of $S$. aureus and $S$. aureus MRSA indicating a great antibacterial effect of these particles. The MIC value was $1.87 \mu \mathrm{g} / \mathrm{mL}$ of $\operatorname{AgNP}(2.2 \times$ $10^{10}$ particles $/ \mathrm{mL}$ ) for both strains of $S$. aureus. This result is relevant because several physiological properties of the burn environment predispose to infection, that is, a major complication of burns [19]. The most common causes of burn wound infections were bacteria, mainly Staphylococcus aureus and methicillin-resistant Staphylococcus aureus (MRSA) [19, 45]. $M R S A$ is an opportunistic bacterial pathogen that causes symptoms ranging from minor skin lesions to sepsis [47]. Furthermore, MRSA colonization is associated with loss of skin grafts and delayed wound healing in burn patients. Thus, the presence of MRSA in a burn unit is a concern because 


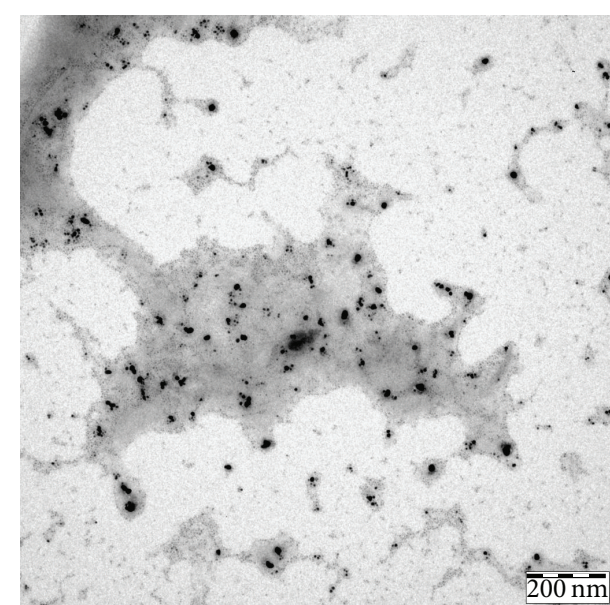

(a)

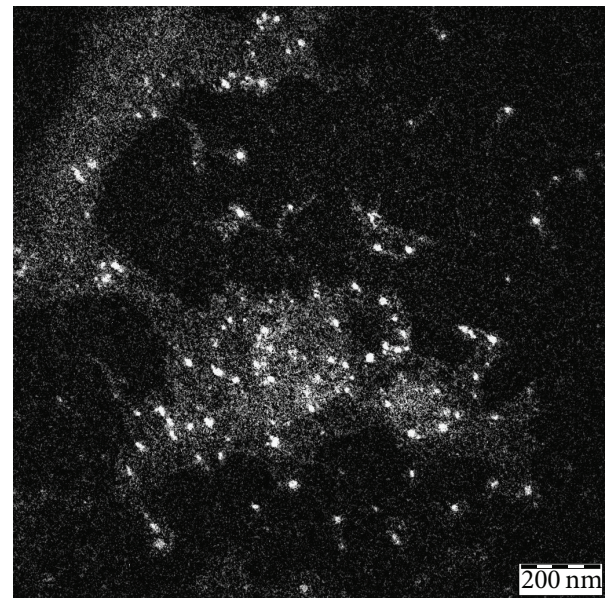

(c)

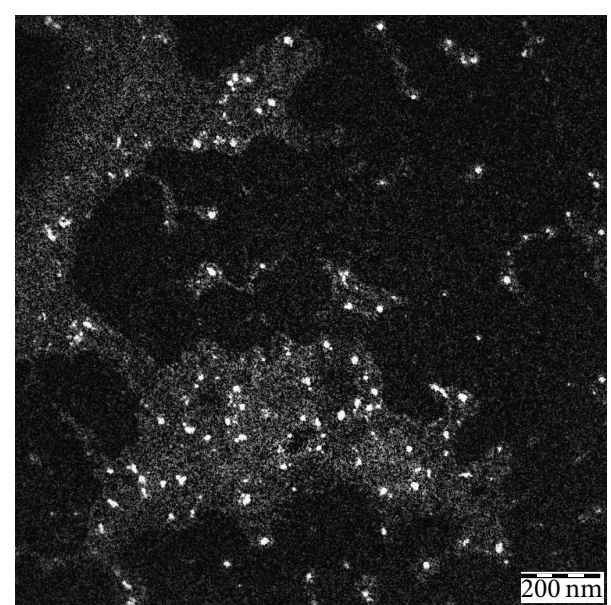

(b)

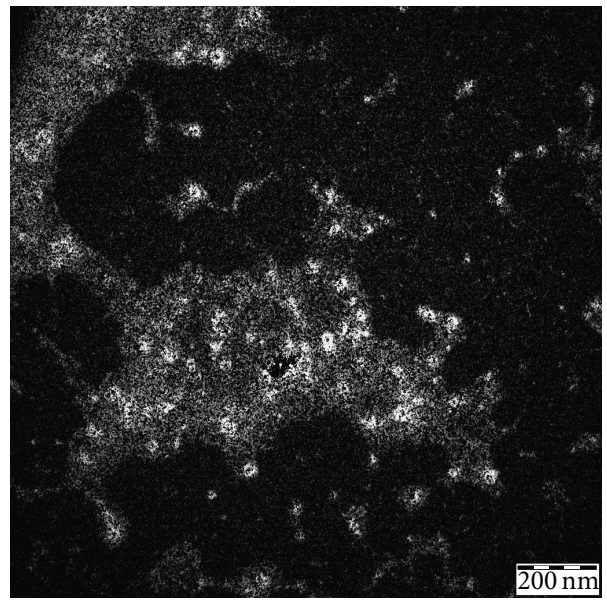

(d)

FIgURE 2: (a) Bright field image of the silver nanoparticles, (b) ESI map for Ag atoms (intense bright white points), and (c) and (d) ESI map for $\mathrm{N}$ and $\mathrm{S}$ atoms, respectively (clouds of white regions around of intense bright white points).

it can increase the morbidity and mortality, increased length of stay, and increased cost of care of burn patients [48]. To decrease these problems, antimicrobial agent, such as sodium sulfadiazine or silver nitrate, is applied in the wound burn. However, microorganisms resistant to topical antimicrobial agents have been reported [49]. Thus, AgNP of this work is an interesting formulation for burn treatment due to its high antimicrobial activity (low MIC value: $1.87 \mu \mathrm{g} / \mathrm{mL}$ ) against $S$. aureus and MRSA.

3.3. In Vivo Activity. Figure 5(a) is an example of burninduced damage on the skin tissue (immediately after the burn-induction). After 28 days of treatment it was possible to observed, macroscopically, the presence of wound healing in Enox and AgNP-Enox groups (Figures 5(d) and 5(e), resp.) compared to control group (Natrosal gel) (Figure 5(b)). In the AgNP group a small wound can be observed (Figure 5(c)). These observations are in agreement with wound contractions, 28 days after the burn, which were 55, 89, 91, and 95\% for control, Enox, AgNP, and AgNP-Enox groups, respectively. The date is indicating of advantage of Enox complex with AgNP. Furthermore, no bleeding was observed in the Enox or AgNP-Enox groups suggesting that the Enox doses $(1 \mathrm{mg} / \mathrm{g}$ of gel) added to AgNP were adequate for this application.

Overall microscopic analysis of HE-stained histological sections obtained from the treatments revealed some qualitative differences in the skin architectural arrangement or cellularity. In control group, granulation tissue in different stages of development, rich in fibroblasts, which differentiate between myofibroblasts, was observed. In AgNP group, myofibroblasts were observed in earlier stage. Similar results were observed by Liu et al. [22] in the wound treatment with silver nanoparticles produced by chemical method. In the Enox group there was granulation tissue in more advanced stage of scar evolution, with highest myofibroblasts density. Similar result was observed for AgNP-Enox group, however, without inflammatory infiltrate predominance. Thus, the AgNP-Enox group showed greater wound healing compared with others groups (Figure 6). 


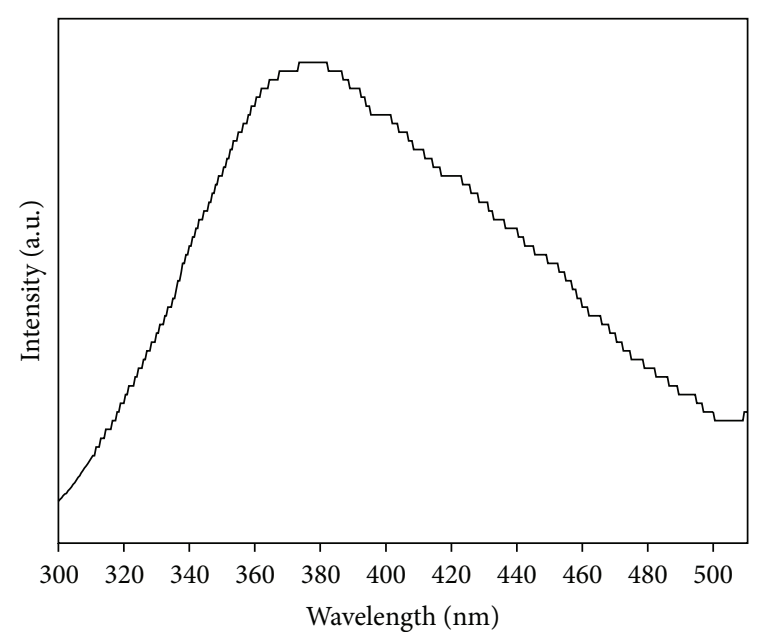

(a)

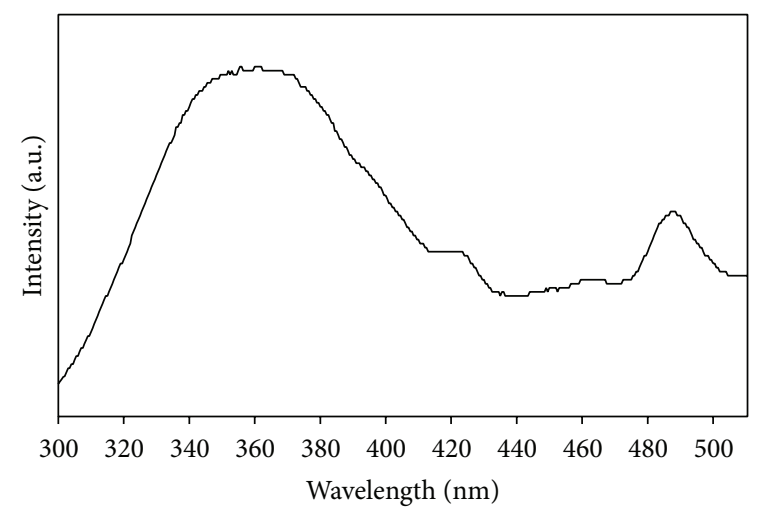

(b)

FIgURE 3: Fluorescence spectra: (a) fungal filtrated before $\mathrm{AgNO}_{3}$ addition, (b) fungal filtrated after $\mathrm{AgNO}_{3}$ addition.

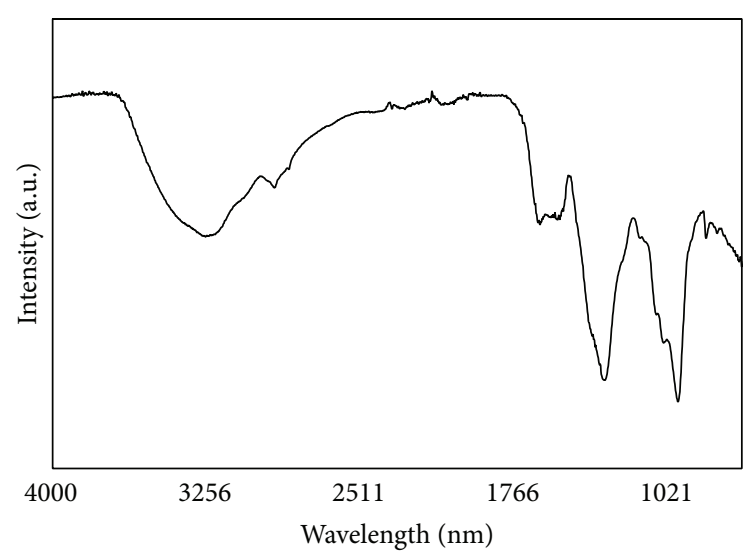

FIGURE 4: FTIR-ATR spectrum of silver nanoparticles.

3.4. In Vivo Toxicity. Different parameters were evaluated to investigate formulations toxicity. This study is very important since silver nanoparticles exhibit toxicity and are not biodegradable. Thus, AgNP penetration in damaged skin and accumulated in organs were evaluated. Figure 7 shows silver nanoparticles concentration in different organs. The results showed that the silver amount found in all organs (liver, kidney, spleen, and lung), except for the skin, was significantly lower in the group treated with AgNP-Enox compared to group treated with AgNP. In the skin, until 7th day after the burn, the silver amount found in the skin of animals treated with AgNP-Enox was significantly higher than the group treated with AgNP. These results demonstrated that silver nanoparticles reached the bloodstream; however, the complex of AgNP with Enox may be helping in the elimination of AgNP. In both formulations lowest silver amount was found in the blood and highest concentration was observed in liver and spleen. In general, nanomaterials are accumulated in these organs that are major organs of the reticuloendothelial system (RES) that are responsible for phagocytosis of foreign bodies. This nanostructure accumulation has already been described in the literature for $\mathrm{TiO}_{2}$ particles, gold, quantum dots, silica, and silver nanoparticles administered by oral and intravenous path [50-56] and others. Despite AgNP presence in different organs, no clear toxicity was observed in the parameters evaluated when the different groups were compared to control group (natrosol gel). No statistical significant difference $(P<0.05)$, in almost all hematological and biochemical parameters, was observed in the Enox, AgNP, and AgNP-Enox groups when compared to control group (natrosol gel) (Tables 1 and 2). Furthermore, the majority of parameters evaluated were within the reference range [57], even though all the groups evaluated are burnt. An increased trend of white cells was verified in Enox, AgNP, and AgNP-Enox groups that can be related with cytokines modulation as described by Tian et al. [6]. In the same groups an increased trend in platelets was also observed indicating that these formulations can be acting in platelet activation mainly in the 7th day after the burn. These results can explain the wound healing acceleration in the treated groups (Enox, AgNP, and AgNP-Enox). Furthermore, according to Table 1, the urea levels were significantly higher $(P<0.001)$ in the AgNP-Enox group when compared with control (natrosol gel), AgNP, and Enox groups, indicating increased proteolysis due to inflammation process.

\section{Conclusion}

This study showed that AgNP and Enox accelerated the wound healing and this acceleration was more pronounced when AgNP was complexed with Enox. This association was responsible for reducing the time required for the differentiation of fibroblasts into hyperactive cells (myofibroblasts) involved in the generation of contractile force in the wound and reversed the inflammatory process more quickly when compared to the standalone application. Furthermore, silver amount found in liver, kidney, spleen, and lung was significantly lower in the group treated with AgNP-Enox when compared to the group treated with AgNP indicating that the complexation of AgNP with Enox may be helping in the excretion of AgNP. No in vivo toxic effect was clearly verified in all parameters evaluated in the treated groups (AgNP, Enox, and AgNP-Enox). There were no significant differences 


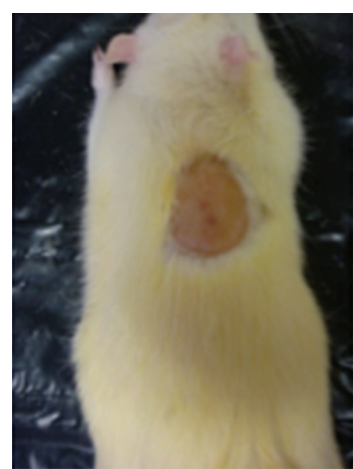

(a)

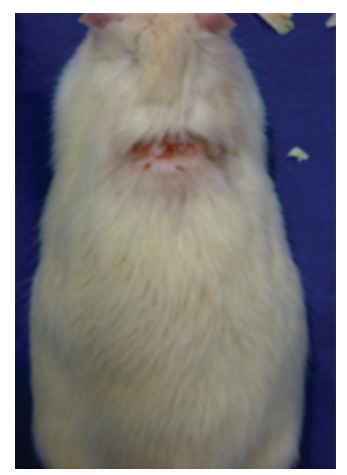

(b)

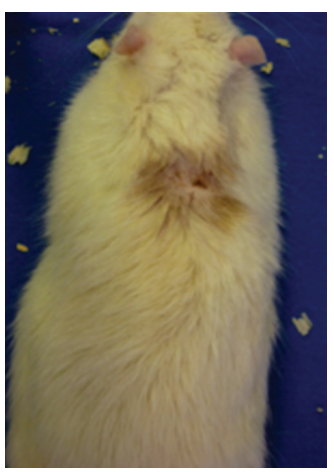

(c)

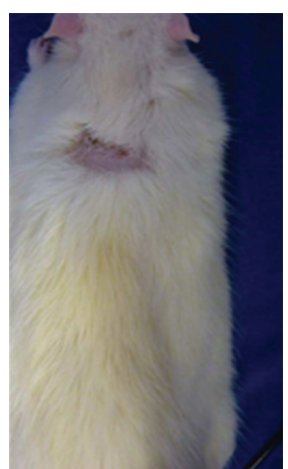

(d)

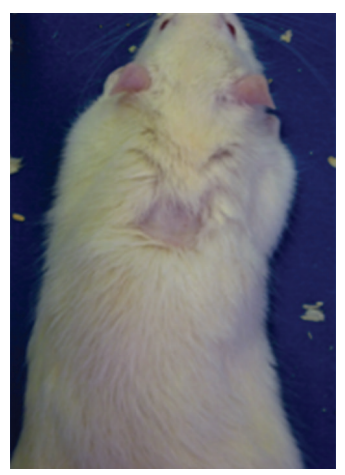

(e)

FiguRE 5: (a) Wound healing condition immediately after burn injury, (b) control (after 28 days of burn wound), (c) AgNP (after 28 days of burn wound), (d) Enox (after 28 days of burn wound), and (e) AgNP-Enox (after 28 days of burn wound).

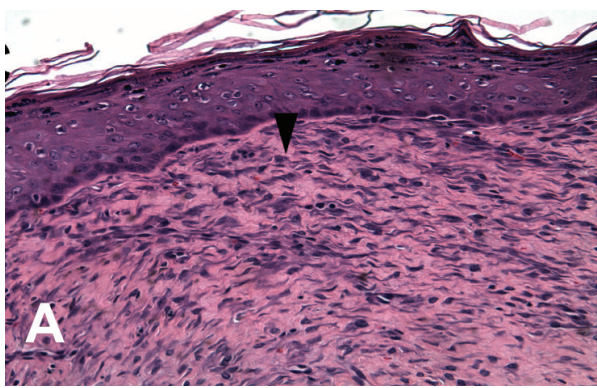

(a)

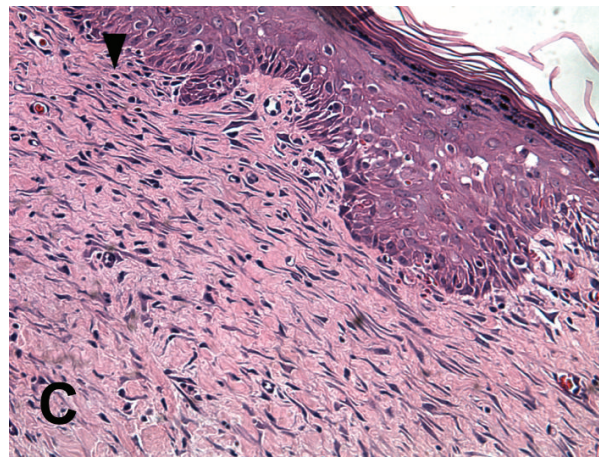

(c)

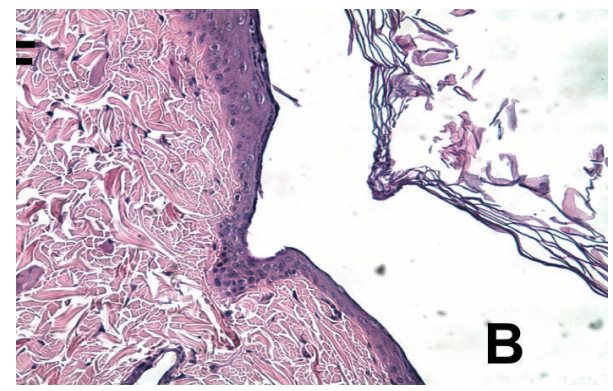

(b)

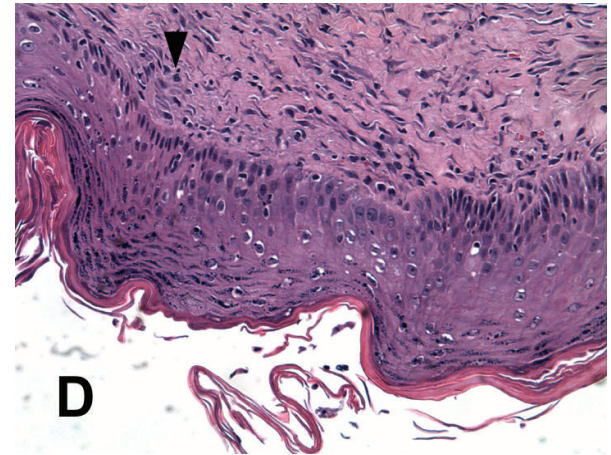

(d)

Figure 6: Longitudinal sections of dorsal skin after 21 days of thermal injury (HE 200x). (a) Contracture area with greater presence of extracellular matrix. Note the intense cellularity and large number of miofibroblasts in rats treated with free natrosol gel ( $\bullet$ ). (b) HE staining after AgNP treatment reveals increases in dermis vascularity and lower amount of miofibroblast, since the higher amount was observed earlier. (c) Contracture region after Enox treatment showing hematoxylin-stained cells, typical of fibroblasts in hyperactive state in the papillary dermis ( $\bullet$. (d) Treatment with AgNP-Enox showing a contracture area with reduced number of myofibroblasts and reduced leukocyte migration $(\bullet)$. Images of rats after 28 days of treatment were not shown because there were similar to the rats treated for 21 days.

in the levels of creatinine, aminotransferases (ALT and AST), and the hematological parameters between the control and all groups treated, despite the systemic penetration of AgNP. However, urea levels in the AgNP-Enox groups, after 7 days of burn injury, were significantly higher when compared with the other groups, indicating increased proteolysis due to inflammation process. Furthermore, a trend in stimulate the platelets production was observed in the groups treated with Enox, AgNP, and AgNP-Enox mainly in the 7th day after the burn. The elimination of these particles from the animals was, probably, by spleen and liver, where a higher silver concentration was found. This work demonstrated an interesting formulation to treatment of burns based on biogenic silver nanoparticles complexed with enoxaparin that improved the wound healing and did not exhibited clearly in vivo toxicity. 
TABLE 1: Biochemistry and hematological analysis of control group, AgNP group, Enox group, and AgNP-Enox group after 7 days of burn injury.

\begin{tabular}{lcccc}
\hline & Control & Enox & AgNP & AgNP-Enox \\
\hline Urea $(\mathrm{mg} / \mathrm{dL})$ & $45.5 \pm 6.91$ & $45.2 \pm 2.86$ & $46.0 \pm 5.79$ & $55.0 \pm 5.10^{*}$ \\
Creatinine $(\mathrm{mg} / \mathrm{dL})$ & $0.45 \pm 0.08$ & $0.43 \pm 0.01$ & $0.47 \pm 0.07$ & $0.46 \pm 0.03$ \\
ALT $(\mathrm{U} / \mathrm{L})$ & $51.7 \pm 9.45$ & $45.2 \pm 5.73$ & $40.7 \pm 5.86$ & $47.4 \pm 6.35$ \\
AST $(\mathrm{U} / \mathrm{L})$ & $79.7 \pm 9.51$ & $77.7 \pm 8.56$ & $78.7 \pm 10.31$ & $68.4 \pm 6.76$ \\
Red cells $(\mathrm{cell} / \mu \mathrm{L}) \times 10^{6}$ & $7.64 \pm 0.833$ & $7.83 \pm 0.563$ & $8.32 \pm 0.470$ & $8.04 \pm 0.396$ \\
Platelet $(\mathrm{cell} / \mu \mathrm{L}) \times 10^{3}$ & $825 \pm 10.25$ & $1217 \pm 15.67$ & $1206 \pm 13.65$ & $956 \pm 9.85$ \\
Hemoglobin $(\mathrm{g} / \mathrm{dL})$ & $15.2 \pm 1.92$ & $13.3 \pm 1.91$ & $14.0 \pm 1.32$ & $14.2 \pm 0.88$ \\
White cells $(\mathrm{cell} / \mu \mathrm{L}) \times 10^{3}$ & $3.80 \pm 0.100$ & $5.15 \pm 0.636$ & $6.50 \pm 1.99$ & $8.27 \pm 1.67$ \\
\hline
\end{tabular}

Data are means $\pm \mathrm{SD}, n=5$ per group. ${ }^{*} P \leq 0.001$ for AgNP-Enox versus control, Enox, and AgNP.

TABLE 2: Biochemistry and hematological analysis of control group, AgNP group, Enox group, and AgNP-Enox group after 28 days of burn injury.

\begin{tabular}{lcccc}
\hline & Control & Enox & AgNP & AgNP-Enox \\
\hline Urea $(\mathrm{mg} / \mathrm{dL})$ & $37.6 \pm 10.4$ & $43.2 \pm 5.06$ & $50.0 \pm 10.61$ & $49.4 \pm 6.65$ \\
Creatinine $(\mathrm{mg} / \mathrm{dL})$ & $0.54 \pm 0.04$ & $0.49 \pm 0.06$ & $0.51 \pm 0.04$ & $0.51 \pm 0.04$ \\
ALT $(\mathrm{U} / \mathrm{L})$ & $34.0 \pm 4.54$ & $33.5 \pm 4.20$ & $38.5 \pm 52.89$ & $37.7 \pm 4.72$ \\
AST $(\mathrm{U} / \mathrm{L})$ & $60.4 \pm 10.11$ & $52.0 \pm 5.77$ & $70.7 \pm 11.03$ & $77.2 \pm 13.89$ \\
Red cells $(\mathrm{cell} / \mu \mathrm{L}) \times 10^{6}$ & $8.00 \pm 0.562$ & $9.07 \pm 0.595$ & $8.23 \pm 0.207$ & $7.75 \pm 0.110$ \\
Platelet $(\mathrm{cell} / \mu \mathrm{L}) \times 10^{3}$ & $829 \pm 13.66$ & $805 \pm 12.4$ & $853 \pm 10.50$ & $789 \pm 11.42$ \\
Hemoglobin $(\mathrm{g} / \mathrm{dL})$ & $14.0 \pm 0.62$ & $14.6 \pm 1.11$ & $15.2 \pm 0.33$ & $14.1 \pm 0.16$ \\
White cells $(\mathrm{cell} / \mu \mathrm{L}) \times 10^{3}$ & $6.95 \pm 1.01$ & $8.22 \pm 1.29$ & $4.22 \pm 0.932$ & $5.30 \pm 0.784$ \\
\hline
\end{tabular}

Data are means $\pm \mathrm{SD}, n=5$ per group.

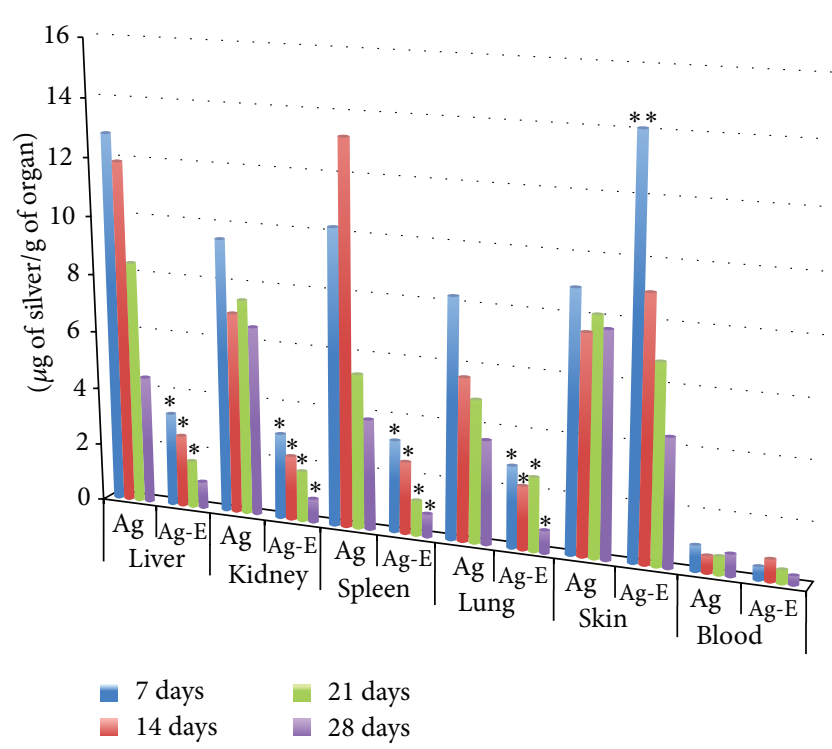

FIGURE 7: Silver concentration in different organs in the groups treated with AgNP and AgNP-Enox (Ag-E). ${ }^{*} P \leq 0.001$ for AgNPEnox versus AgNP, ${ }^{* *} \mathrm{P} \leq 0.01$ for AgNP-Enox versus AgNP.

\section{Conflict of Interests}

The authors confirm that they have no financial and personal interests in the work described.

\section{Acknowledgments}

The authors are grateful to CNPq and FAPESP for financial support. This is a contribution of the NanoBioss (MCTI) and the National Institutes of Science, Technology and Innovation on Complex Functional Materials (Inomat).

\section{References}

[1] M. G. P. Barretto, M. G. N. F. Costa, M. C. V. F. Serra, J. B. Afiune, H. E. P. Praxedes, and E. Pagani, "Estudo comparativo entre tratamento convencional e tratamento com heparina tópica para a analgesia de queimaduras," Revista da Associação Médica Brasileira, vol. 56, no. 1, pp. 51-55, 2010.

[2] T. D. J. Heunis and L. M. T. Dicks, "Nanofibers offer alternative ways to the treatment of skin infections," Journal of Biomedicine and Biotechnology, vol. 2010, Article ID 510682, 10 pages, 2010.

[3] I. Tocco, B. Zavan, F. Bassetto, and V. Vindigni, "Nanotechnology-based therapies for skin wound regeneration," Journal of Nanomaterials, vol. 2012, Article ID 714134, 11 pages, 2012.

[4] J. A. Flegg, H. M. Byrne, M. B. Flegg, and D. L. McElwain, "Wound healing angiogenesis: the clinical implications of a simple mathematical model," Journal of Theoretical Biology, vol. 300, pp. 309-316, 2012.

[5] P. S. Melo, P. D. Marcato, S. C. Huber et al., "Nanoparticles in treatment of thermal injured rats: is it safe?" Journal of Physics: Conference Series, vol. 304, no. 1, Article ID 012027, 2011.

[6] J. Tian, K. K. Y. Wong, C.-M. Ho et al., "Topical delivery of silver nanoparticles promotes wound healing," ChemMedChem, vol. 2, no. 1, pp. 129-136, 2007. 
[7] R. Serra, G. Buffone, A. De Franciscis et al., "Skin grafting followed by low-molecular-weight heparin long-term therapy in chronic venous leg ulcers," Annals of Vascular Surgery, vol. 26, no. 2, pp. 190-197, 2012.

[8] M. J. Saliba Jr., "Heparin in the treatment of burns: a review," Burns, vol. 27, no. 4, pp. 349-358, 2001.

[9] J. Lu, T. Xu, M. Yang, X. Xu, and B. Wu, "Heparin for the treatment of burns (protocol)," Cochrane Database of Systematic Reviews, vol. 12, Article ID CD009483, 2011.

[10] C. Mathay, S. Giltaire, F. Minner, E. Bera, M. Hérin, and Y. Poumay, "Heparin-binding EGF-like growth factor is induced by disruption of lipid rafts and oxidative stress in keratinocytes and participates in the epidermal response to cutaneous wounds," Journal of Investigative Dermatology, vol. 128, no. 3, pp. 717-727, 2008.

[11] F. A. F. S. Orgaes, M. C. Lyra, O. F. R. Júnior, and H. A. Gonella, "Estudo histopatológico do uso de heparina tópica em queimaduras por escaldo em ratos," Revista Brasileira de Cirurgia Plástica, vol. 22, no. 1, pp. 39-44, 2007.

[12] C. Pazzini, P. D. Marcato, L. B. Prado et al., "Polymeric nanoparticles of enoxaparin as a delivery system: in vivo evaluation in normal rats and in a venous thrombosis rat model," Journal of Nanoscience and Nanotechnology, vol. 15, no. 7, pp. 4837-4843, 2015.

[13] P. Agbenorku, S. Fugar, J. Akpaloo, P. E. Hoyte-Williams, Z. Alhassan, and F. Agyei, "Management of severe burn injuries with topical heparin: the first evidence-based study in Ghana," International Journal of Burns and Trauma, vol. 3, no. 1, pp. 3036, 2013.

[14] O. F. Oken, A. O. Yildirim, V. S. Una et al., "The effect of prophylactic dose of a low molecular weight heparin on skin wound healing of rats," Acta Cirurgica Brasileira, vol. 24, no. 6, pp. 471-475, 2009.

[15] S. C. Huber, P. D. Marcato, R. M. Barbosa, N. Duran, and J. M. Annichino-Bizzacchi, "In vivo toxicity of enoxaparin encapsulated in mucoadhesive nanoparticles: topical application in a wound healing model," Journal of Physics: Conference Series, vol. 429, no. 1, Article ID 012031, 2013.

[16] Y.-K. Song and C.-K. Kim, "Topical delivery of low-molecularweight heparin with surface-charged flexible liposomes," Biomaterials, vol. 27, no. 2, pp. 271-280, 2006.

[17] M. Tajkarimi, D. Iyer, M. Tarrannum et al., "The effect of silver nanoparticle size and coating on Escherichia coli," JSM Nanotechnology \& Nanomedicine, vol. 2, no. 2, article 1025, 2014.

[18] J. Fong and F. Wood, "Nanocrystalline silver dressings in wound management: a review," International Journal of Nanomedicine, vol. 1, no. 4, pp. 441-449, 2006.

[19] T. Dai, Y.-Y. Huang, S. K. Sharma, J. T. Hashmi, D. B. Kurup, and M. R. Hamblin, "Topical antimicrobials for burn wound infections," Recent Patents on Anti-Infective Drug Discovery, vol. 5, no. 2, pp. 124-151, 2010.

[20] K. H. Kwan, X. Liu, and K. W. Yeung, "Silver nanoparticles improve wound healing," Nanomedicine, vol. 6, no. 4, pp. 595596, 2011.

[21] K. Chaloupka, Y. Malam, and A. M. Seifalian, "Nanosilver as a new generation of nanoproduct in biomedical applications," Trends in Biotechnology, vol. 28, no. 11, pp. 580-588, 2010.

[22] X. Liu, P.-Y. Lee, C.-M. Ho et al., "Silver nanoparticles mediate differential responses in keratinocytes and fibroblasts during skin wound healing," ChemMedChem, vol. 5, no. 3, pp. 468-475, 2010.
[23] P. L. Nadworny, J. Wang, E. E. Tredget, and R. E. Burrell, "Antiinflammatory activity of nanocrystalline silver-derived solutions in porcine contact dermatitis," Journal of Inflammation, vol. 7, article 13, 2010.

[24] C. Sundaramoorthi, S. Devarasu, and P. K. Vengadesh, "Antimicrobial and wound healing activity of silver nanoparticles synthesized from streptomyces aureofaciens," International Journal of Pharmaceutical Research and Development, vol. 2, no. 12, pp. 69-75, 2011.

[25] A. B. G. Lansdown, "A pharmacological and toxicological profile of silver as an antimicrobial agent in medical devices," Advances in Pharmacological Sciences, vol. 2010, Article ID 910686, 16 pages, 2010.

[26] J. Y. Chung and M. E. Herbert, "Myth: silver sulfadiazine is the best treatment for minor burns," Western Journal of Medicine, vol. 175, no. 3, pp. 205-206, 2001.

[27] E. M. Mintz, D. E. George, and S. Hsu, "Silver sulfadiazine therapy in widespread bullous disorders: potential for toxicity," Dermatology Online Journal, vol. 14, no. 3, p. 19, 2008.

[28] N. Durán, P. D. Marcato, R. De Conti, O. L. Alves, F. T. M. Costa, and M. Brocchi, "Potential use of silver nanoparticles on pathogenic bacteria, their toxicity and possible mechanisms of action," Journal of the Brazilian Chemical Society, vol. 21, no. 6, pp. 949-959, 2010.

[29] L. Kvitek, A. Panacek, R. Prucek et al., "Antibacterial activity and toxicity of silver-nanosilver versus ionic silver," Journal of Physics: Conference Series, vol. 304, no. 1, Article ID 012029, 2011.

[30] J. B. Wright, K. Lam, A. G. Buret, M. E. Olson, and R. E. Burrell, "Early healing events in a porcine model of contaminated wounds: effects of nanocrystalline silver on matrix metalloproteinases, cell apoptosis, and healing," Wound Repair and Regeneration, vol. 10, no. 3, pp. 141-151, 2002.

[31] R. Jayakumar, M. Prabaharan, P. T. Sudheesh Kumar, S. V. Nair, and H. Tamura, "Biomaterials based on chitin and chitosan in wound dressing applications," Biotechnology Advances, vol. 29, no. 3, pp. 322-337, 2011.

[32] S. Lu, W. Gao, and H. I. Gu, "Construction, application and biosafety of silver nanocrystalline chitosan wound dressing," Burns, vol. 34, no. 5, pp. 623-628, 2008.

[33] J. Tang, L. Xiong, S. Wang et al., "Influence of silver nanoparticles on neurons and blood-brain barrier via subcutaneous injection in rats," Applied Surface Science, vol. 255, no. 2, pp. 502-504, 2008.

[34] M. J. Piao, K. A. Kang, I. K. Lee et al., "Silver nanoparticles induce oxidative cell damage in human liver cells through inhibition of reduced glutathione and induction of mitochondriainvolved apoptosis," Toxicology Letters, vol. 201, no. 1, pp. 92100, 2011.

[35] K. Park, E.-J. Park, I. K. Chun et al., "Bioavailability and toxicokinetics of citrate-coated silver nanoparticles in rats," Archives of Pharmacal Research, vol. 34, no. 1, pp. 153-158, 2011.

[36] K. Kang, H. Jung, and J.-S. Lim, "Cell death by polyvinylpyrrolidine-coated silver nanoparticles is mediated by ROS-dependent signaling," Biomolecules \& Therapeutics, vol. 20, no. 4, pp. 399405, 2012.

[37] A. K. Gade, P. Bonde, A. P. Ingle, P. D. Marcato, N. Durán, and M. K. Rai, "Exploitation of Aspergillus niger for synthesis of silver nanoparticles," Journal of Biobased Materials and Bioenergy, vol. 2, no. 3, pp. 243-247, 2008.

[38] N. Durán, P. D. Marcato, G. I. H. de Souza, O. L. Alves, and E. Esposito, "Antibacterial effect of silver nanoparticles produced 
by fungal process on textile fabrics and their effluent treatment," Journal of Biomedical Nanotechnology, vol. 3, no. 2, pp. 203-208, 2007.

[39] N. Durán, P. D. Marcato, O. L. Alves, G. I. H. de Souza, and E. Esposito, "Mechanistic aspects of biosynthesis of silver nanoparticles by several Fusarium oxysporum strains," Journal of Nanobiotechnology, vol. 3, article 8, pp. 1-7, 2005.

[40] P. Li, J. Li, C. Wu, and Q. Wu, "Synergistic antibacterial effects of $\beta$-lactam antibiotic combined with silver nanoparticles," Nanotechnology, vol. 16, no. 9, pp. 1912-1917, 2005.

[41] A. Sakarcan, Ö. Sehirli, A. Velioglu-Övünç et al., "Ginkgo biloba extract improves oxidative organ damage in a rat model of thermal trauma," Journal of Burn Care \& Rehabilitation, vol. 26, no. 6, pp. 515-524, 2005.

[42] P. Mukherjee, M. Roy, B. P. Mandal et al., "Green synthesis of highly stabilized nanocrystalline silver particles by a nonpathogenic and agriculturally important fungus T. asperellum," Nanotechnology, vol. 19, no. 7, Article ID 075103, 2008.

[43] M. Gajbhiye, J. Kesharwani, A. Ingle, A. Gade, and M. Rai, "Fungus-mediated synthesis of silver nanoparticles and their activity against pathogenic fungi in combination with fluconazole," Nanomedicine: Nanotechnology, Biology, and Medicine, vol. 5, no. 4, pp. 382-386, 2009.

[44] M. S. Ali, H. A. Al-Lohedan, M. Z. Rafiquee, A. M. Atta, and A. O. Ezzat, "Spectroscopic studies on the interaction between novel polyvinylthiol-functionalized silver nanoparticles with lysozyme," Spectrochimica Acta Part A: Molecular and Biomolecular Spectroscopy, vol. 135, pp. 147-152, 2015.

[45] Z. Karim, R. Adnan, and M. S. Ansari, "Low concentration of silver nanoparticles not only enhances the activity of horseradish peroxidase but alter the structure also," PLoS ONE, vol. 7, no. 7, Article ID e41422, 2012.

[46] M. Fayaz, C. S. Tiwary, P. T. Kalaichelvan, and R. Venkatesan, "Blue orange light emission from biogenic synthesized silver nanoparticles using Trichoderma viride," Colloids and Surfaces B: Biointerfaces, vol. 75, no. 1, pp. 175-178, 2010.

[47] C. G. Mayhall, “The epidemiology of burn wound infections: then and now," Clinical Infectious Diseases, vol. 37, no. 4, pp. 543-550, 2003.

[48] C. Andrade, S. Champagne, D. Caruso, K. Foster, and K. Reynolds, "Methicillin-resistant Staphylococcus aureus: an assessment of environmental contamination in a burn center," American Journal of Infection Control, vol. 37, no. 6, pp. 515-517, 2009.

[49] J. M. Embil, J. A. McLeod, A. M. Al-Barrak et al., "An outbreak of methicillin resistant Staphylococcus aureus on a burn unit: potential role of contaminated hydrotherapy equipment," Burns, vol. 27, no. 7, pp. 681-688, 2001.

[50] C. McNulty, G. L. Rodgers, and J. E. Mortensen, "An overview of the topical antimicrobial agents used in the treatment of burn wounds," Journal of Continuing Education Topics \& Issues, vol. 273, pp. 74-78, 2004.

[51] K. Loeschner, N. Hadrup, K. Qvortrup et al., "Distribution of silver in rats following 28 days of repeated oral exposure to silver nanoparticles or silver acetate," Particle and Fibre Toxicology, vol. 8, article 18, 2011.

[52] D. P. K. Lankveld, A. G. Oomen, P. Krystek et al., "The kinetics of the tissue distribution of silver nanoparticles of different sizes," Biomaterials, vol. 31, no. 32, pp. 8350-8361, 2010.
[53] W. H. de Jong, W. I. Hagens, P. Krystek, M. C. Burger, A. J. A. M. Sips, and R. E. Geertsma, "Particle size-dependent organ distribution of gold nanoparticles after intravenous administration," Biomaterials, vol. 29, no. 12, pp. 1912-1919, 2008.

[54] G. Xie, J. Sun, G. Zhong, L. Shi, and D. Zhang, "Biodistribution and toxicity of intravenously administered silica nanoparticles in mice," Archives of Toxicology, vol. 84, no. 3, pp. 183-190, 2010.

[55] J. Wang, G. Zhou, C. Chen et al., "Acute toxicity and biodistribution of different sized titanium dioxide particles in mice after oral administration," Toxicology Letters, vol. 168, no. 2, pp. 176185, 2007.

[56] R. S. H. Yang, L. W. Chang, J.-P. Wu et al., "Persistent tissue kinetics and redistribution of nanoparticles, quantum dots 705, in mice: ICP-MS quantitative assessment," Environmental Health Perspectives, vol. 115, no. 9, pp. 1339-1343, 2007.

[57] V. B. V. Lapchik, V. G. M. Mattaraia, and G. M. Ko, Cuidados e Manejo de Animais de Laboratório, Atheneu, São Paulo, Brazil, 2009. 

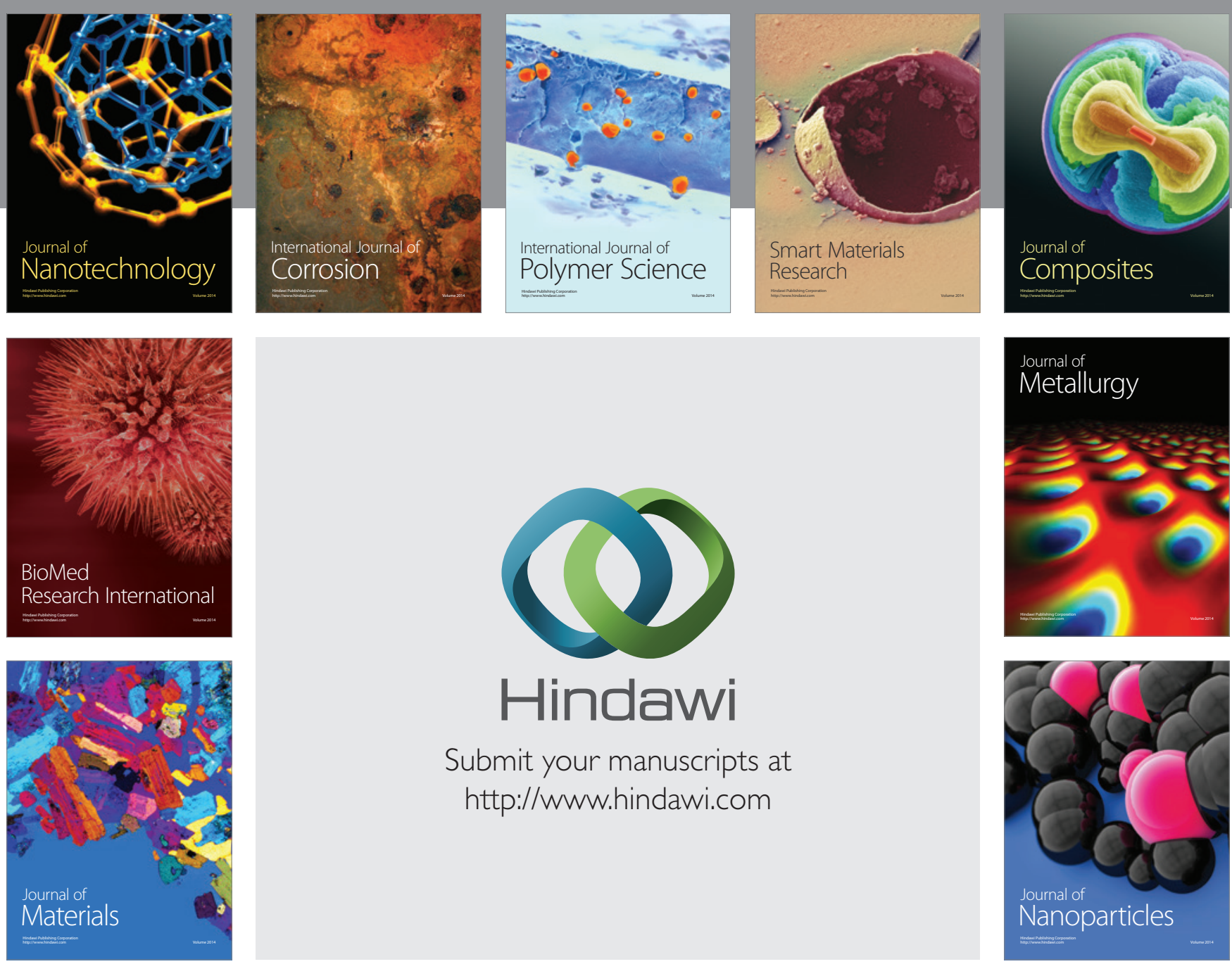

Submit your manuscripts at http://www.hindawi.com
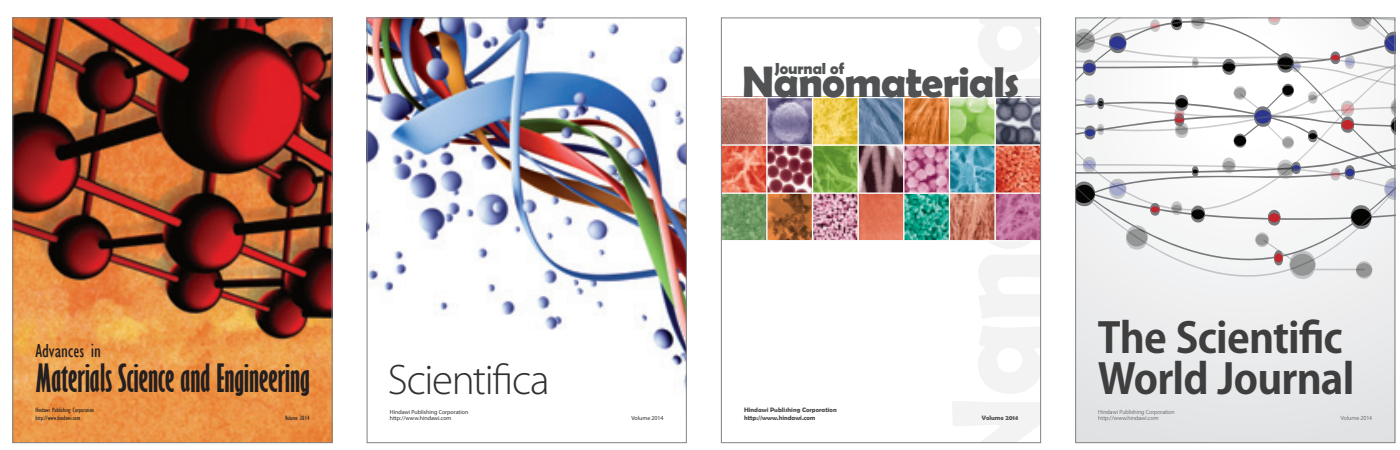

\section{The Scientific World Journal}
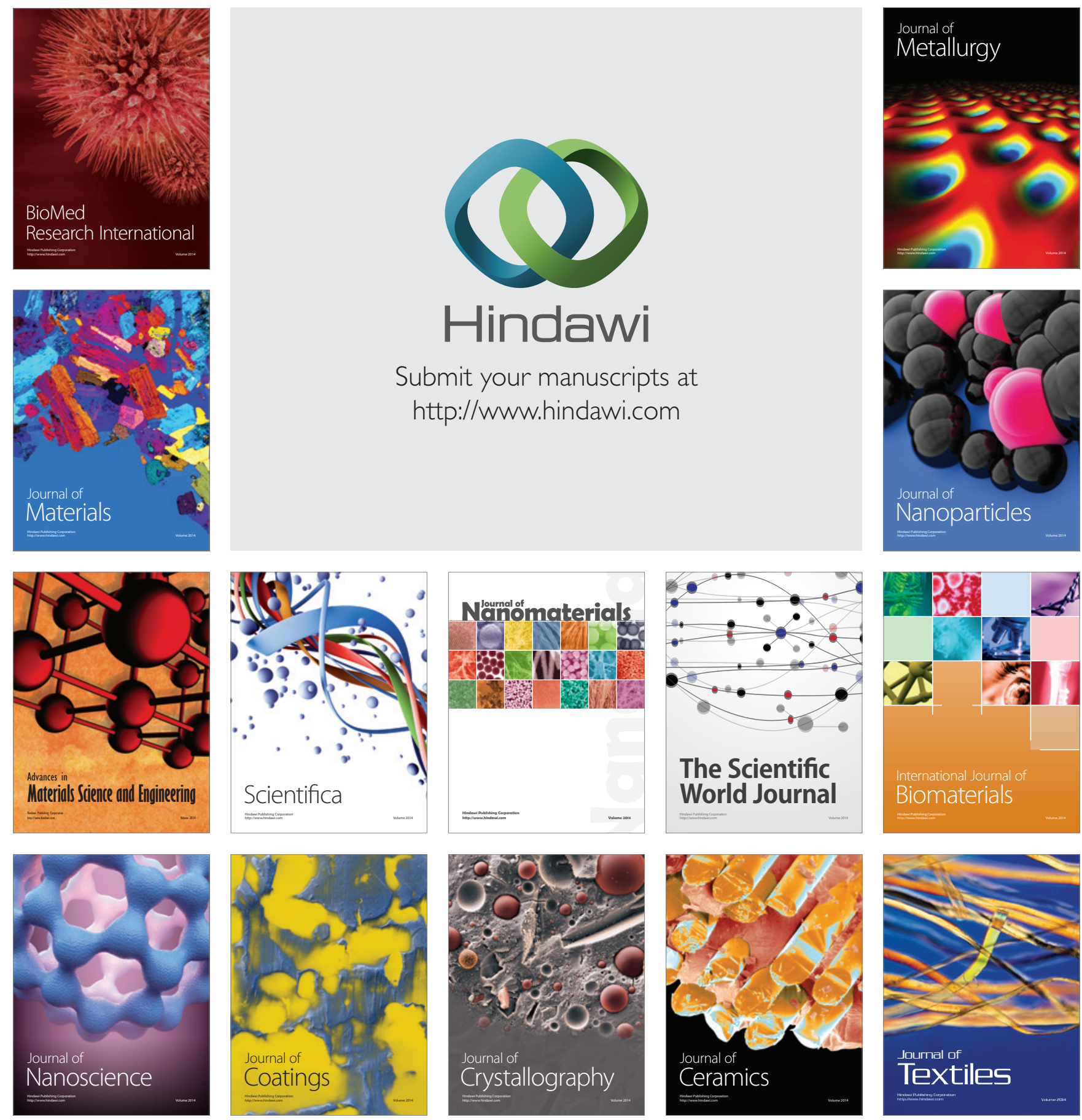